\title{
Longstanding eosinophilic gastroenteritis of more than 20 years
}

\author{
Hugh J Freeman MD
}

\begin{abstract}
Longstanding eosinophilic gastroenteritis of more than 20 years. HJ Freeman. Can J Gastroenterol 2009;23(9):632-634.
\end{abstract}

Eosinophilic gastroenteritis (EGE) is an eosinophil-predominant inflammatory process that may be detected in endoscopic gastric or intestinal biopsies. The long-term natural history and effects of EGE treatment are not known. A 44-year-old man with abdominal pain was treated with oral ketotifen and followed for more than 20 years. Ketotifen provided symptomatic benefit, with prompt clinical relapse if the drug was discontinued. However, despite the use of ketotifen, the endoscopic abnormalities persisted and appeared to progress. Gastric body and antral mucosal folds appeared thickened, erythematous and friable, with minimal erosive change. Later, even during long asymptomatic periods suggesting clinical 'remission', inflammatory polypoid change, previously described in children with EGE, developed with mucosal 'pock-marking' and apparent scarring. Ketotifen treatment does not appear to prohibit or reverse the inflammatory process in the gastric mucosa in EGE, although long-term effects of steroids may be avoided. In the future, treatment of EGE may involve monoclonal antibody agents that target the specific biological effects of the eosinophil, apparently central to this unusual inflammatory process.

Key Words: Eosinophilic gastroenteritis; Eosinophils; Gastric polyps; Ketotifen; Mast cells

Cosinophilic gastroenteritis (EGE) is a distinct, pathoElogically defined disorder characterized by an eosinophilpredominant mucosal inflammatory process. Most often, the disorder is detected during endoscopic investigation for abdominal pain or diarrhea. Other causes of gastric and intestinal mucosal eosinophilia require exclusion, including parasites and drug-induced causes. Occasionally, the muscle wall or serosa may also be involved (1-3).

EGE is now more readily recognized owing, in large part, to the endoscopic imaging methods that evaluate abdominal pain and diarrhea, along with the increased use of mucosal biopsy (4). Interestingly, in a report from a single clinical practice (5), almost $1 \%$ of all endoscopic biopsy studies during an eight-year period showed changes that led to a diagnosis of EGE, suggesting that this may be a relatively common clinical disorder that is not well recognized. Definition of EGE, however, may be difficult because the ranges of normal and abnormal eosinophil numbers in gastric and intestinal mucosa are not standardized, the eosinophil inflammatory process may be patchy or diffuse, and recognition of eosinophils is heavily dependent on specific fixation methods (6).

Treatment of EGE has traditionally focused on resolution or improvement in symptoms, usually with corticosteroids, and, in some, quantitation of eosinophil numbers in pretreatment and

\author{
Gastro-entérite à éosinophiles datant de plus de \\ 20 ans
}

La gastro-entérite à éosinophiles (GEÉ) est un processus inflammatoire à prédominance éosinophilique que l'on peut dépister par la biopsie endoscopique gastrique ou intestinale. L'histoire naturelle et les effets à long terme du traitement de la GEÉ sont inconnus. Un homme de 44 ans souffrant de douleurs abdominales a été traité au moyen de kétotifène oral et suivi pendant plus de 20 ans. Le kétotifène soulageait ses symptômes, mais la rechute clinique suivait rapidement à l'arrêt du médicament. Or, malgré l'utilisation du kétotifène, les anomalies endoscopiques ont persisté et ont semblé progresser. Le corps de l'estomac et les replis de la muqueuse antrale sont devenus épaissis, érythémateux et friables, avec des signes minimes d'érosion. Plus tard, même durant de longues périodes asymptomatiques faisant penser à une rémission clinique, des anomalies polypoïdes inflammatoires, précédemment décrites chez des enfants atteints de GEÉ, se sont développées, accompagnées de cicatrices muqueuses en creux et apparentes. Le traitement par kétotifène ne semble pas bloquer $\mathrm{ni}$ inverser le processus inflammatoire dans la muqueuse gastrique en présence de GEÉ, bien que les effets à long terme des corticostéroïdes puissent être évités. Éventuellement, le traitement de la GEÉ pourrait inclure des anticorps monoclonaux qui ciblent les effets biologiques spécifiques des éosinophiles exerçant apparemment un rôle central dans ce processus inflammatoire inhabituel.

post-treatment biopsies. Most often, reports concerning EGE, particularly those that claim therapeutic success, are limited in their duration to weeks or months of follow-up. Future evaluation and treatment of EGE will also ultimately depend on an improved appreciation for the long-term natural history of this unusual inflammatory disorder and the emergence of potential new treatments, including the potential use of biological agents.

\section{CASE PRESENTATION}

A 44-year-old man first presented with abdominal pain in 1988, leading to a diagnosis of EGE. His clinical course up to 1992 included steroid treatment. In 1992, the patient's abdominal pain had resolved with ketotifen 2 mg twice daily, and eosinophil counts in peripheral blood and gastric biopsies had partially normalized. This case was detailed in a previous publication in this Journal (6). From 1992 to 1997, he remained asymptomatic on this dosage of ketotifen, with a stable weight ranging from $85 \mathrm{~kg}$ to $87 \mathrm{~kg}$. Additional upper endoscopic evaluations remained unchanged, with hyperemia and prominence of the gastric body and antral folds (Figure 1). Gastric biopsies continued to show increased numbers of eosinophils, while duodenal biopsies remained normal. Stains for Helicobacter pylori were negative. His peripheral blood eosinophil count remained persistently elevated at $1.8 \times 10^{9} / \mathrm{L}$ to $2.5 \times 10^{9} / \mathrm{L}$ (normal $0 \times 10^{9} / \mathrm{L}$ to $0.50 \times 10^{9} / \mathrm{L}$ ). 


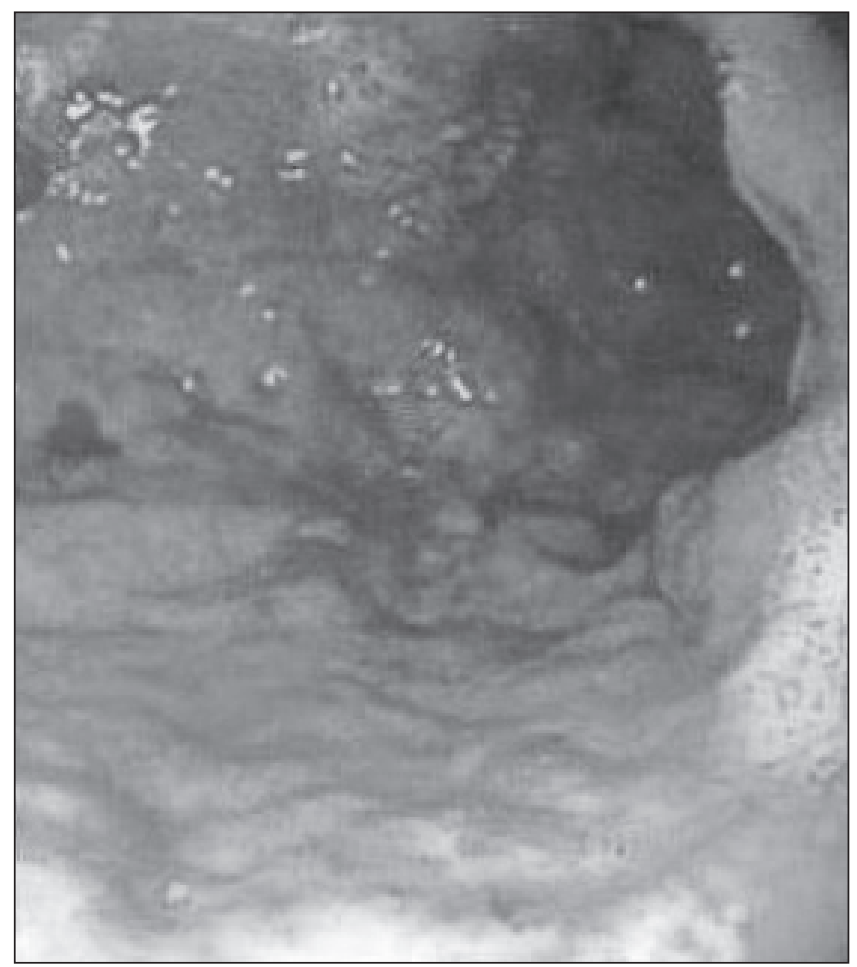

Figure 1) Erythematous and prominent gastric body folds. Formalinfixed gastric mucosal biopsies showed numerous eosinophils

In 1998, the patient's ketotifen was empirically discontinued and his pain promptly recurred. Endoscopic evaluation revealed prominent erythematous gastric body and antral folds, with focal antral erosions. Biopsies revealed a mixed mucosal inflammatory infiltrate with prominent eosinophils. Treatment with ketotifen $2 \mathrm{mg}$ twice daily along with the empirical addition of omeprazole $20 \mathrm{mg}$ four times a day led to the resolution of his abdominal pain. Omeprazole was discontinued after one month and ketotifen alone was continued. Endoscopic evaluations yielding similar findings were repeated in 2002 and 2004, despite the absence of symptoms. Thickened and erythematous gastric body folds were seen with diffuse antral and body mucosal erythema, erosions and inflammatory polyps (Figure 2). All biopsies showed an eosinophil-predominant inflammatory process. In 2004, the ketotifen was again stopped; however, abdominal pain recurred within approximately three months, with diarrhea and weight loss.

Because of persistent symptoms, endoscopic evaluations of the upper and lower gastrointestinal tracts were performed in 2005. Colonoscopy was normal, as were colonic biopsies. Esophagogastroscopy revealed a normal esophagus and duodenum. The gastric mucosa was abnormal, with thickened gastric body rugae, unusual pock-marked areas of erosion, and apparent mucosal scarring and prepyloric antral mucosal inflammatory polypoid change (Figure 3). Multiple gastric mucosal biopsies showed persistent eosinophilic gastritis with a normal esophagus and duodenum. The ketotifen was started again at a dose of $2 \mathrm{mg}$ twice daily and continued to the present time.

In 2007, similar endoscopic and biopsy changes were present. Additional gastric biopsies were also sent for DNA polymerase chain reaction analysis and were negative for any clonal B cell or $\mathrm{T}$ cell population (Cancer Genetics Laboratory, BC Cancer Agency, Vancouver, British Columbia). In 2008, more than

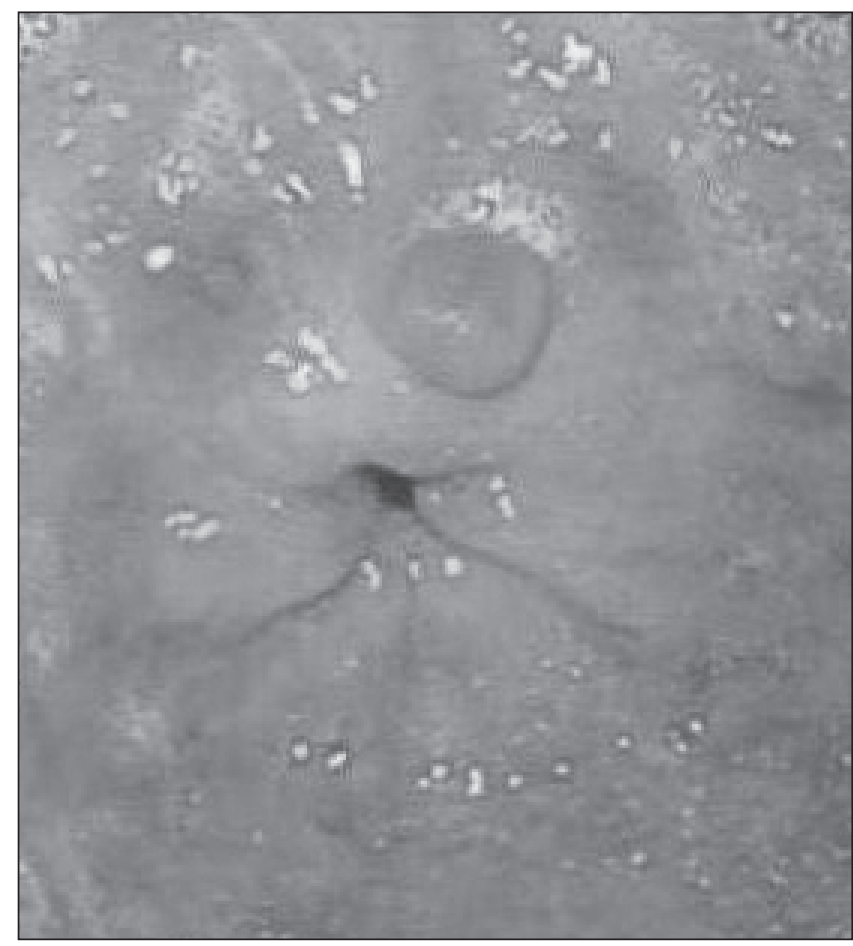

Figure 2) Antral erythema with friable mucosa and erosive change. Prepyloric inflammatory polypoid change is present

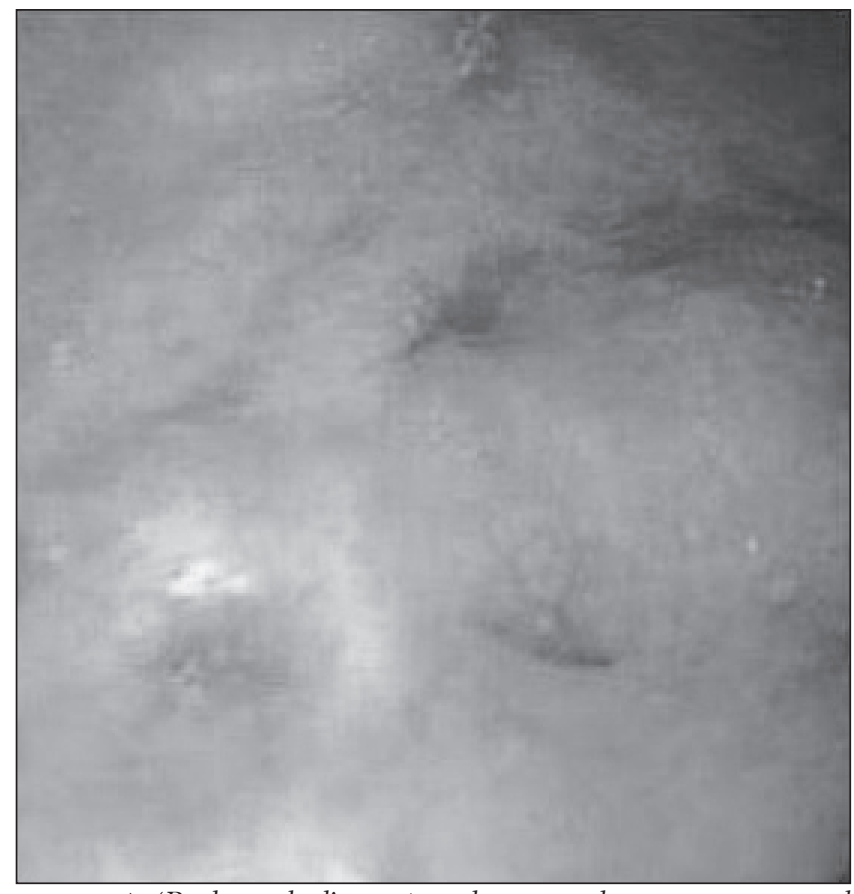

Figure 3) 'Pock-marked' erosive change and apparent mucosal scarring

20 years since the initial definition of the patient's diagnosis of EGE, he was asymptomatic on ketotifen $2 \mathrm{mg}$ twice daily.

\section{DISCUSSION}

The present report documents persistent and evolving mucosal changes in an adult with longstanding EGE followed for 
more than 20 years. During this time, this unusual eosinophilpredominant inflammatory process persisted despite long symptom-free periods on virtually continuous ketotifen therapy. Ketotifen is an H1-class antihistamine that has been used to treat a number of allergic disorders, including extrinsic asthma. Its precise mechanism of action is not known. Ketotifen reportedly stabilizes mast cell membranes and possibly impairs the chemotactic migration of eosinophils (and possibly other cells) into tissues. In addition, others have suggested that it may impair histamine release and leukotriene production. Clinical improvement and a reduction of eosinophilic infiltrates from gastric biopsies with ketotifen were previously reported (6-8) during relatively short-term treatment, including the previous report of the present case as well as in children with gastric polyps, suggesting that continous ketotifen treatment might be a safer clinical alternative to other forms of therapy including long-term corticosteroids. However, the imaging and biopsy findings in the present case, collected over a period of more than 20 years of virtually continous ketotifen therapy, suggest that the medication may be useful for symptom control although it does not prevent evolution of the endoscopic changes and histopathological effects associated with this unusual and ongoing eosinophil-predominant inflammatory process.

The pathogenesis of EGE is very poorly understood. However, information regarding eosinophil biology in both health and disease is developing rapidly (9). Eosinophil granules contain a number of potentially cytotoxic proteins that might have deleterious gastric mucosal effects. Among others, these include major basic protein, eosinophil-derived neurotoxin, eosinophil cationic protein and eosinophilic peroxidase. Direct cellular damage to the gastric mucosa may result if degranulation and sudden release of these substances occurred. Eosinophils also produce inflammatory mediators, (ie, leukotriene $\mathrm{C} 4$ and platelet activating factor, which could cause mucosal damage). Alternatively, eosinophils may indirectly activate mast cells to release histamines and other potentially harmful

\section{REFERENCES}

1. Khan S, Orenstein SR. Eosinophilic gastroenteritis. Gastroenterol Clin North Am 2008;37:333-48.

2. Straumann A. Idiopathic eosinophilic gastrointestinal diseases in adults. Best Pract Res Clin Gastroenterol 2008;22:481-96.

3. Talley NJ, Shorter RG, Phillips SF, Zinsmeister AR. Eosinophilic gastroenteritis: A clinicopathological study of patients with disease of the mucosa, muscle layer and subserosal tissues. Gut 1990;31:54-8.

4. Katz AJ, Goldman H, Grand RJ. Gastric mucosal biopsy in eosinophilic gastroenteritis. Gastroenterology 1977;73:705-9.

5. Gorrepati N, Desai H, Fox S, Amin M, Stecevic V, Desai T. An eight-year study of 30 consecutive patients with eosinophilic gastroenteritis in one gastroenterology practice: Eosinophilic gastroenteritis is more common than previously appreciated and may not necessarily require corticosteroid therapy. Gastroenterology 2007;132:A610 (Abst).

6. Freeman HJ. Histological evaluation of gastric biopsies for diagnosis and treatment in eosinophilic gastroenteritis. Can J Gastroenterol 1993;7:343-8.

7. Melamed I, Feanny SJ, Sherman PM, Roifman CM. Benefit of ketotifen in patients with eosinophilic gastroenteritis. Am J Med 1991;90:310-14.

8. Jimenez-Rivera C, Ngan B, Jackson R, Ahmed N. Gastric pseudopolyps in eosinophilic gastroenteritis. J Pediatr Gastroenterol Nutr 2005;40:83-6. inflammatory mediators. Much has emerged in recent years regarding the molecular steps involved in intestinal eosinophil development and mucosal trafficking, the important role of the transcription factor GATA-1, the eosinophil-selective cytokine interleukin-5 and the eotaxin subfamily of chemokines (9). The rationale for the use of ketotifen was related, in part, to its potential role in limiting this process. However, a long list of other agents to empirically treat EGE has emerged including proton pump inhibitors (5), octreotide (10), corticosteroids (4) and leukotriene antagonists (11). This likely reflects the limited therapeutic effectiveness of currently available treatment regimens, even in the short-term, and may eventually lead to the use of new biological agents that will require long-term study to determine if the natural history of EGE can be altered.

Only limited information is available concerning the relationship of EGE to other conditions that also display this intriguing eosinophil-predominant inflammatory process in gastric or intestinal tissues. Mucosal eosinophilic infiltrates are also not entirely unique to EGE because these may occur in other inflammatory mucosal disorders such as ulcerative colitis or Crohn's disease (1-3). In addition, eosinophils may be detected in gastric or intestinal mucosa during parasitic infections and with medication reactions. EGE has been rarely reported to coexist with celiac disease $(12,13)$. Moreover, an eosinophil-predominant inflammatory process involving the esophageal mucosa has been increasingly recognized in recent years but its precise relationship, if any, to EGE is poorly defined (14). Finally, eosinophils in the gastrointestinal tract may also be increased in the hypereosinophilic syndrome, a rare disorder comparable with EGE, in which the treatment goals are aimed at lowering the eosinophil level (2). In this disorder, defined on the basis of peripheral blood eosinophil counts, biological agents, specifically monoclonal antibodies to interleukin-5 such as mepolizumab (15-17), have been evaluated in a preliminary short-term fashion, raising the potential for their use in future clinical trials with EGE patients.

9. Fulkerson PC, Rothenberg ME. Origin, regulation and physiological function of intestinal eosinophils. Best Pract Res Clin Gastroenterol 2008;22:411-23.

10. Rausch T, Gyr K, Wegmann W, Germer M, Meier R. Symptomatic therapy of severe diarrhea in eosinophilic gastroenteritis with the somatostatin analog octreotide. Schweiz Med Wochenschr 1997;127:S9-S13.

11. Neustrom MR, Friesen C. Treatment of eosinophilic gastroenteritis with montelukast. J Allergy Clin Immunol 1999;104:506.

12. Bennett RA, Whitelock T III, Kelly JL Jr. Eosinophilic gastroenteritis, gluten enteropathy, and dermatitis herpetiformis. Am J Dig Dis 1974;19:1154-61.

13. Butterfield JH, Murray JA. Eosinophilic gastroenteritis and glutensensitive enteropathy in the same patient. J Clin Gastroenterol 2002;34:552-3.

14. Prasad GA, Talley NJ. Eosinophilic esophagitis in adults. Gastroenterol Clin N Am 2008;37:349-68.

15. Ploetz SG, Simon HU, Darsow U, et al. Use of anti-interleukin-5 antibody in the hypereosinophilic syndrome with eosinophilic dermatitis. N Engl J Med 2003;349:2334-9.

16. Garrett JK, Jameson SC, Thomson B, et al. Anti-interleukin-5 (mepolizumab) therapy for hypereosinophilic syndromes. J Allergy Clin Immunol 2004;113:115-9.

17. Rothenberg ME, Klion AD, Roufosse FE, et al; Mepolizumab HES Study Group. Treatment of patients with the hypereosinophilic syndrome with mepolizumab. N Engl J Med 2008;358:1215-28. 


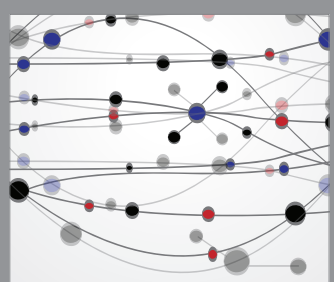

The Scientific World Journal
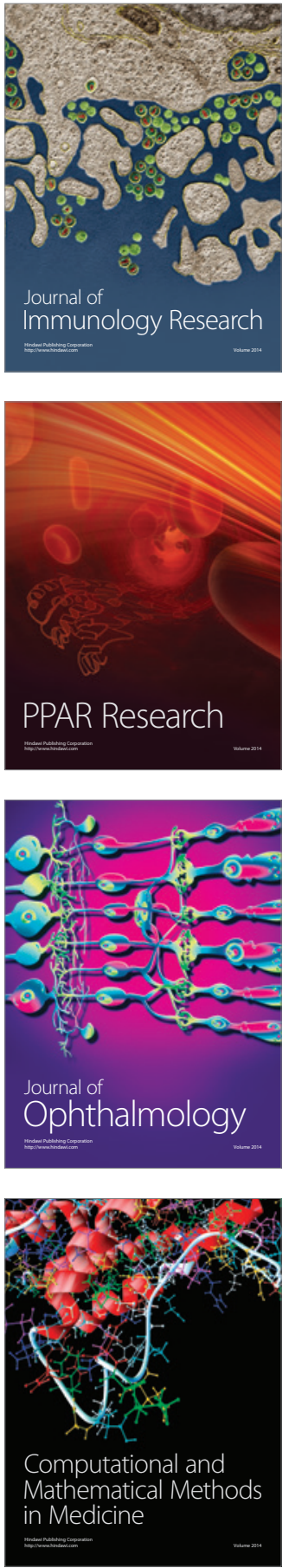

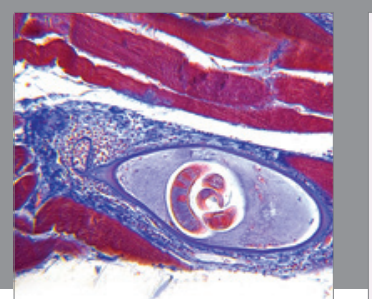

Gastroenterology Research and Practice

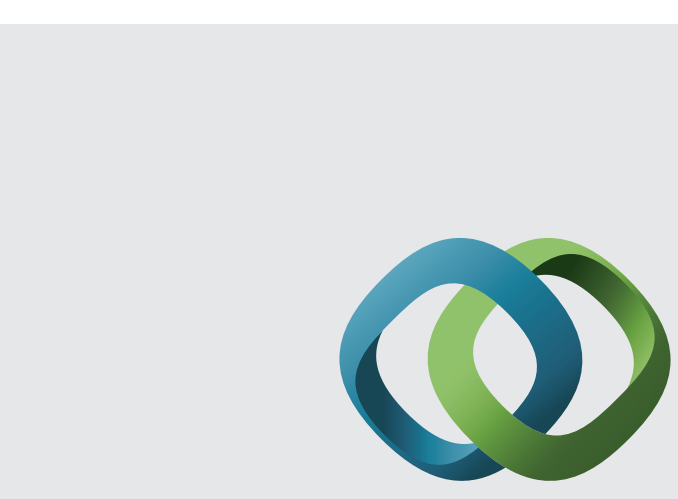

\section{Hindawi}

Submit your manuscripts at

http://www.hindawi.com
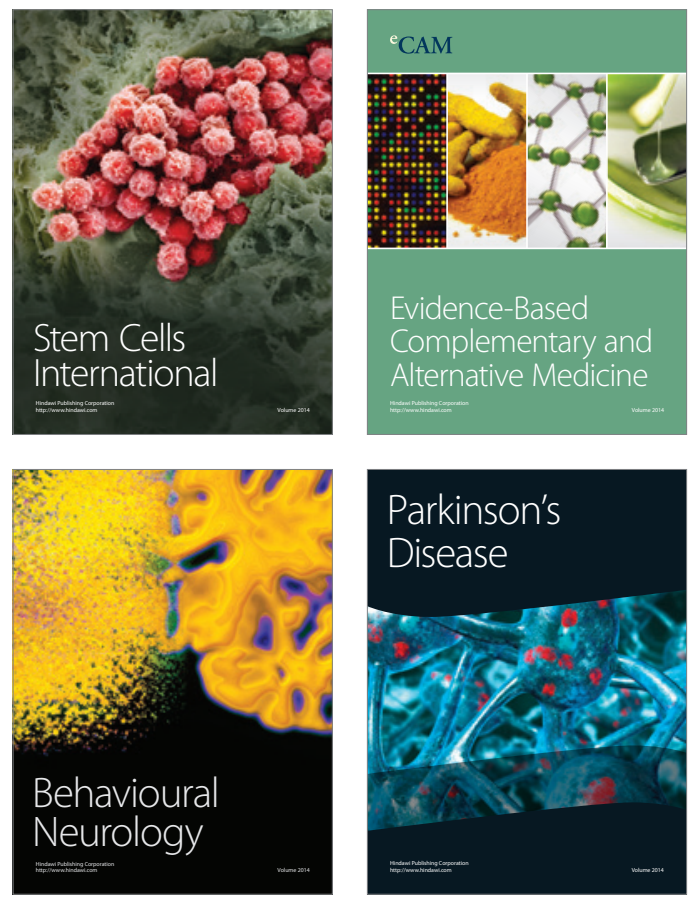
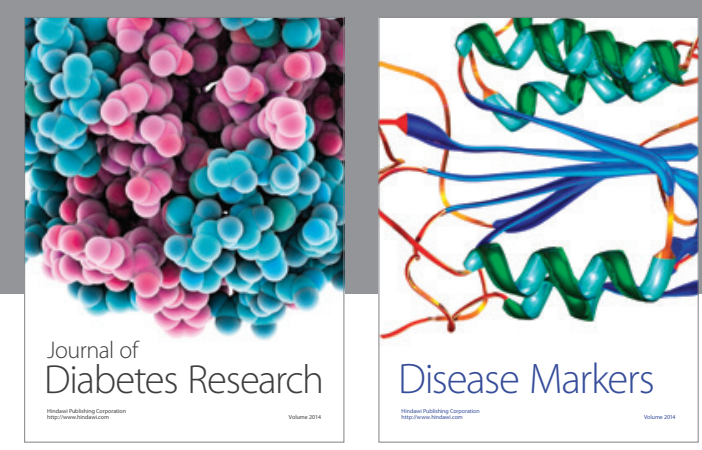

Disease Markers
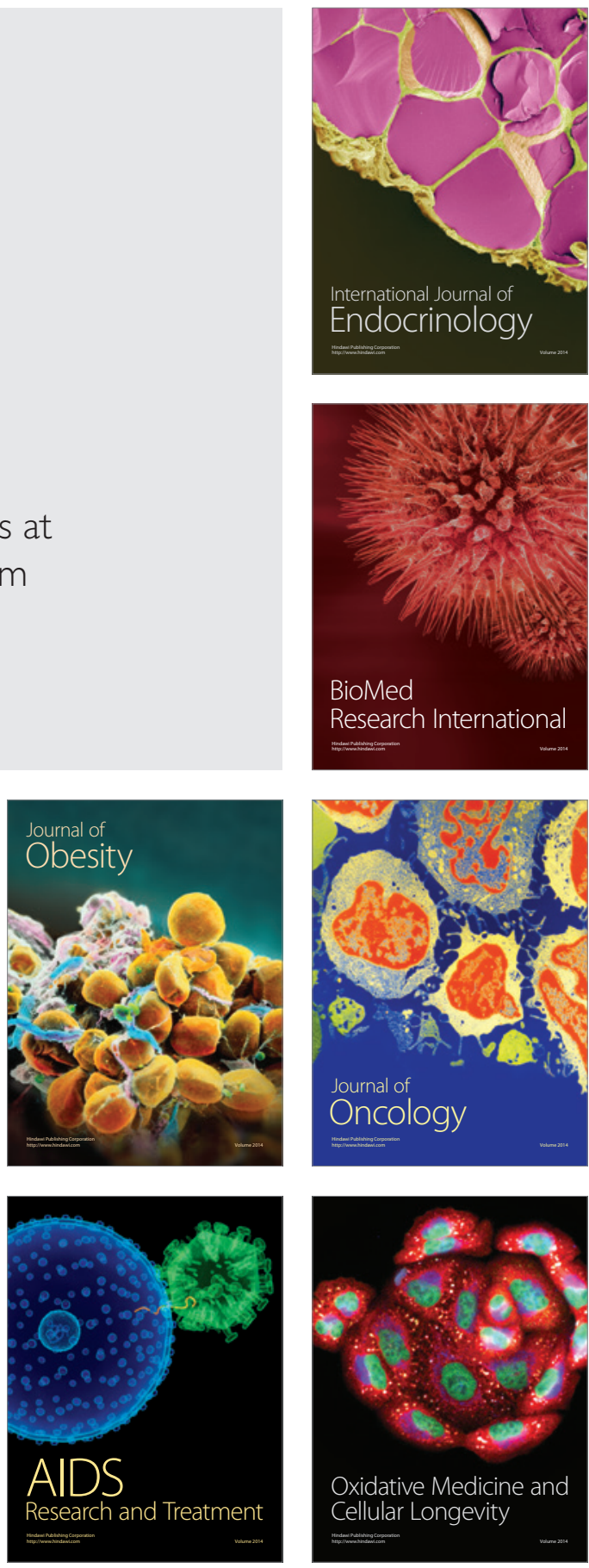